\title{
Effect of the compact Ti layer on the efficiency of dye-sensitized solar cells assembled using stainless steel sheets
}

\author{
Lijian Menga,b,d,*, Mingxing $\mathrm{Wu}^{\mathrm{c}}$, Yongmei Wang ${ }^{\mathrm{d}}$, Wei Guo ${ }^{\mathrm{d}}$, Chunyu Ma ${ }^{\mathrm{e}}$, Tingli Ma ${ }^{\mathrm{d}, *}$, Rui Silva ${ }^{\mathrm{a}}$ \\ a Departamento de Física, Instituto Superior de Engenharia do Porto/Instituto Politécnico do Porto, Rua Dr. António Bernardino de Almeida, 431, 4200-072 Porto, Portugal \\ b Centro de Física, Universidade do Minho, 4800-058 Guimarães, Portugal \\ c Department of Chemistry and Material Science, Key Laboratory of Inorganic Nano-materials of Hebei Province, Hebei Normal University, 050024 Shijiazhuang, China \\ d State Key Laboratory of Fine Chemicals, School of Chemical Engineering, Dalian University of Technology, 116024 Dalian, China \\ e Key Laboratory of Materials Modification by Laser, Ion and Electron Beams, Dalian University of Technology, 116024 Dalian, China
}

\section{A R T I C L E I N F O}

\section{Article history:}

Received 18 July 2012

Received in revised form

26 December 2012

Accepted 26 December 2012

Available online 11 January 2013

\section{Key words:}

Dye-sensitized solar cell

DSSC

Titanium

Stainless steel

Flexible

Impedance spectroscopy

\begin{abstract}
A B S T R A C T
Titanium films have been deposited on stainless steel metal sheets using dc magnetron sputtering technique at different substrate temperatures. The structure of the titanium films strongly depend on the substrate temperature. The titanium film deposited at the substrate temperature lower than $300{ }^{\circ} \mathrm{C}$ has a loose flat sheet grains structure and the titanium film prepared at the substrate temperature higher than $500{ }^{\circ} \mathrm{C}$ has a dense nubby grains structure. The DSSC assembled using stainless steel sheet coated with titanium film deposited at high substrate temperature has a low charge transfer resistance in the $\mathrm{TiO}_{2} / \mathrm{Ti}$ interface and results in a high conversion efficiency. The DSSC assembled using stainless steel sheet coated with titanium film deposited at temperature higher than $500{ }^{\circ} \mathrm{C}$ has higher conversion efficiency than that assembled using titanium metal sheet as the substrate. The maximum conversion efficiency, $2.26 \%$ is obtained for DSSC assembled using stainless steel sheet coated with titanium film deposited at $700{ }^{\circ} \mathrm{C}$ substrate temperature, which is about $70 \%$ of the conversion efficiency of the FTO reference cell used in this study.
\end{abstract}

(c) 2013 Elsevier B.V. All rights reserved.

\section{Introduction}

The way we produce and use energy today is not sustainable. Firstly, our main fossil fuel sources - oil, coal and gas - are finite natural resources, and we are depleting them at a rapid rate. Secondly, energy production and use, particularly of fossil fuels, have a number of environmental impacts including air pollution, greenhouse gas emissions and adverse impacts on ecosystems. A fully sustainable renewable power supply is the only way we can secure energy for all and avoid environmental catastrophe. The sun provides an effectively unlimited supply of energy that we can use to generate electricity and heat. The solar energy that reaches the Earth's surface is the largest carbon-free energy source, which could be harvested with photovoltaic or photogalvanic devices. Although the silicon-based solar cells are still dominating the photovoltaic market, several alternatives to Si-based solar cells have become available toward substantially reducing the cost of production. Dyesensitized solar cells (DSSC) are an alternative to silicon devices as they can be cost-effective, light-weight, portable and flexible.

\footnotetext{
* Corresponding author. Tel.: +351 962325429; fax: +351 228321159.

E-mail addresses: ljm@isep.ipp.pt (L. Meng), Tinglima3@gmail.com (T. Ma).
}

Since the prototype of a DSSC was reported in 1991 by Gratzel and his coworker [1], it has aroused intense interest owing to its low cost, simple preparation procedure, and benign effect on the environment compared with traditional photovoltaic devices. Recently, a certified photoelectric conversion efficiency of $11 \%$ has been achieved [2]. However, the traditional DSSC have an inherent disadvantage of using glass as a substrate material, which makes the cells unsuitable for certain applications except for the high material cost. The fabrication of light-weight, flexible and lowcost DSSC using roll-to-roll mass production can be realized by replacing the glass substrate with polymer or metal foil substrates. Indium-doped tin oxide coated polyethyleneterephtalate(ITO-PET) andpolyethylenenaphtalate(ITO-PEN) are the most used conductive polymer substrate. However, their low temperature tolerance needs an alternative deposition or post-treatment technique for the electrode materials, compared with those have been used for glass substrate. As the maximum temperature these polymer substrates can withstand is about $150^{\circ} \mathrm{C}$, the most used colloidal method for preparing the $\mathrm{TiO}_{2}$ photoelectrode is not suitable for these polymer substrates because it needs to be sintered at $450-500^{\circ} \mathrm{C}$ in order to make high quality interconnection between the $\mathrm{TiO}_{2}$ nanoparticles and with the substrate. Although many studies have attempted to alleviate the problem by introducing new methods to prepare nanoporous $\mathrm{TiO}_{2}$ photoelectrodes on conducting polymer 
substrates at low temperature [3-8] and a maximum conversion efficiency of $7.6 \%$ has been achieved $[9,10]$, a convenient and efficient approach has yet to be proposed.

Metal foil is an alternative substrate material for flexible DSSC. The use of metal foil substrates in flexible DSSC has been studied actively in the past few years mainly because of their endurance of high temperature processing used in $\mathrm{TiO}_{2}$ photoelectrode preparation [11-18]. The most used metal substrate materials are titanium and stainless steel (SS). The advantage of titanium is its high stability, it cannot be corroded in iodine-based electrode. However, its price is much higher than SS. The SS is cheap, but the stability is not very high. To reduce the cost and improve the stability, it is convenient to deposit a thin protecting layer on a cheap substrate, for instance, SS. The use of different protecting layers, such as $\mathrm{SiO}_{x}$, ITO, denseTiO ${ }_{2}$ on the SS substrate has been reported $[11,17,18]$. In the present work, the titanium protecting layer has been deposited on the SS by dc sputtering technique at different substrate temperatures. The influence of the substrate temperature on the structure property of these titanium layers and on efficiency of the DSSC assembled using them have been studied. A comparison of a SS substrate system to a conventional FTO glass substrate system has been made.

\section{Experimental}

The SS sheets used in the experiments were commercial 304 SS with a thickness of $0.2 \mathrm{~mm}$. The SS sheets were first washed using detergent, and then cleaned in a detergent solution, ethanol and acetone separately using an ultrasonic bath for $15 \mathrm{~min}$ in each step. The cleaned SS sheets were then transferred to the vacuum chamber and coated with titanium layer using dc magnetron sputtering technique. The sputtering target was titanium metal disk with a diameter of $60 \mathrm{~mm}$ and a purity of $99.99 \%$. Before the depositions, the vacuum chamber was pumping down to $3 \times 10^{-3} \mathrm{~Pa}$. And then the argon gas was introduced into the chamber by mass flow controller. The sputtering pressure was set at $0.7 \mathrm{~Pa}$. The sputtering current and the cathode potential were kept at $0.48 \mathrm{~A}$ and $0.44 \mathrm{kV}$, separately. The substrate temperature was varied from room temperature (RT) to $700^{\circ} \mathrm{C}$. The deposition time was $60 \mathrm{~min}$. The thickness of these titanium layers was about $1000 \mathrm{~nm}$ measured by SEM. A mesoporous $\mathrm{TiO}_{2}$ electrode was prepared by traditional doctor-blading technique. In detail, a thin layer $\mathrm{TiO}_{2}$ paste was coated on Ti sheet. Then the $\mathrm{TiO}_{2}$ film was sintered at $200^{\circ} \mathrm{C}$ for $15 \mathrm{~min}$. Repeats the process above mentioned two times and a 3 layers of $\mathrm{TiO}_{2}$ film was obtained. After sintered at $500^{\circ} \mathrm{C}$ for $30 \mathrm{~min}$, the mesoporous nanocrystalline $\mathrm{TiO}_{2}$ film was completely fabricated. The thickness of the nanocrystalline $\mathrm{TiO}_{2}$ film was about $12-13 \mu \mathrm{m}$. For comparison study, the same process was not only applied for titanium metal sheet, but also for Ti-coated SS and FTO glass substrates. These $\mathrm{TiO}_{2}$ electrodes were sensitized with N719 (Ru(II)L2(NCS)2:2TBA, where $\mathrm{L}=2,2^{\prime}$-bipyridyl-4,4'-dicarboxylic acid) dye by soaking them in an ethanol solution of N719 dye $(0.5 \mathrm{mM})$ for $12 \mathrm{~h}$ at room temperature. The counter electrode was FTO glass coated with Pt and the electrolyte contains of $0.06 \mathrm{M}$ of Lil, 0.6 M 1-propyl-3methylimidazolium iodide, $0.03 \mathrm{M} \mathrm{I}_{2}, 0.5 \mathrm{M}$ 4-tert-butyl pyridine, and $0.1 \mathrm{M}$ guanidinium thiocyanate in acetonitrile.

Surface morphologies of the titanium films prepared at different substrate temperatures were characterized by scanning electron microscopy (SEM, FEI HITACHI 15 S-4800). The XRD experiments were carried out with an automatic X-ray powder diffractometer (D/Max 2400, RIGAKU). Photocurrent-voltage performance of the DSSC was conducted under simulated AM 1.5 illumination $\left(I=100 \mathrm{~mW} \mathrm{~cm}^{-2}\right.$, Solar Light Co., INC., USA) with a Keithley digital source meter (Keithley 2601, USA). Cells with an active area

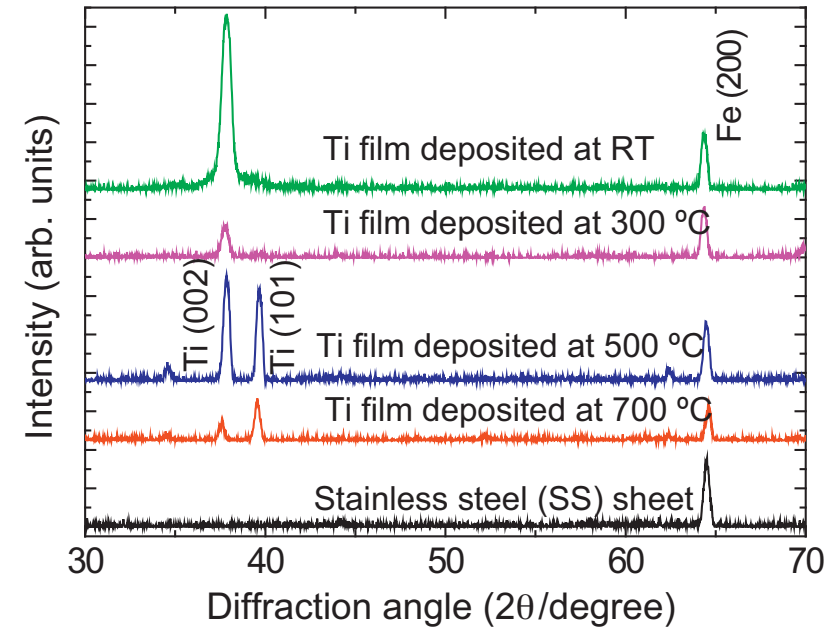

Fig. 1. XRD patterns of titanium layers deposited at different substrate temperatures.

of $0.25 \mathrm{~cm}^{2}$ were tested. The EIS experiment was characterized in two-electrode system using a computer-controlled potentiostat (ZeniumZahner, Germany) in darkness. The measured frequency ranged from $10^{-1}$ to $10^{6} \mathrm{~Hz}$, the bias was $-0.75 \mathrm{~V}$, and the ac amplitude was set to $10 \mathrm{mV}$.

\section{Results and discussion}

Figure 1 shows the XRD patterns of the Ti films deposited at different substrate temperatures on SS sheets. For comparison, the XRD pattern of bare SS substrate is also given in Fig. 1. It can be observed that the Ti films deposited at substrate temperature lower than $300^{\circ} \mathrm{C}$ show a strong orientation along the (002) direction (PDF card file 44-1294). When the substrate temperature is higher than $500^{\circ} \mathrm{C}$, the $\left(\begin{array}{lll}1 & 0 & 1\end{array}\right)$ diffraction peak appears. This ( 10101$)$ orientation dominates the growth direction as the substrate temperature is $700^{\circ} \mathrm{C}$. The intensity ratio of the $\mathrm{I}\left(\begin{array}{ll}101) / \mathrm{I}(002) \\ 0\end{array}\right)$ has been calculated and shown in Fig. 2. It can be seen that this ratio has a small increase as the substrate temperature is increased from RT to $300^{\circ} \mathrm{C}$. However, the ratio shows a very quick increase with the substrate temperature when it is higher than $300^{\circ} \mathrm{C}$. It indicates that the growth direction tends to be along the (101) direction when the substrate temperature is higher than $300^{\circ} \mathrm{C}$. The mean grain size along the (002) direction has been estimated from Scherrer's formula. The results have been shown in Fig. 2 . The grain size increases linearly from 15 to $27 \mathrm{~nm}$ as the substrate temperature is

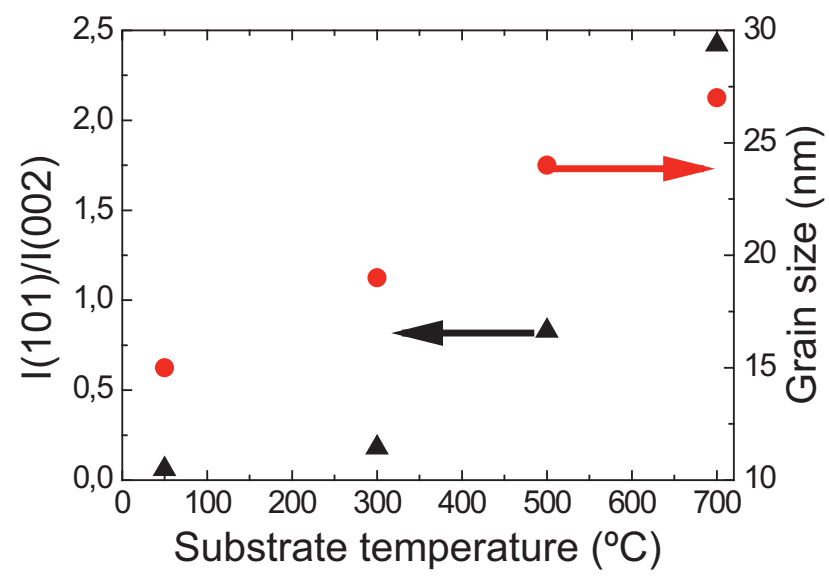

Fig. 2. Peak intensity ratio and grain size as a function of the substrate temperature. 

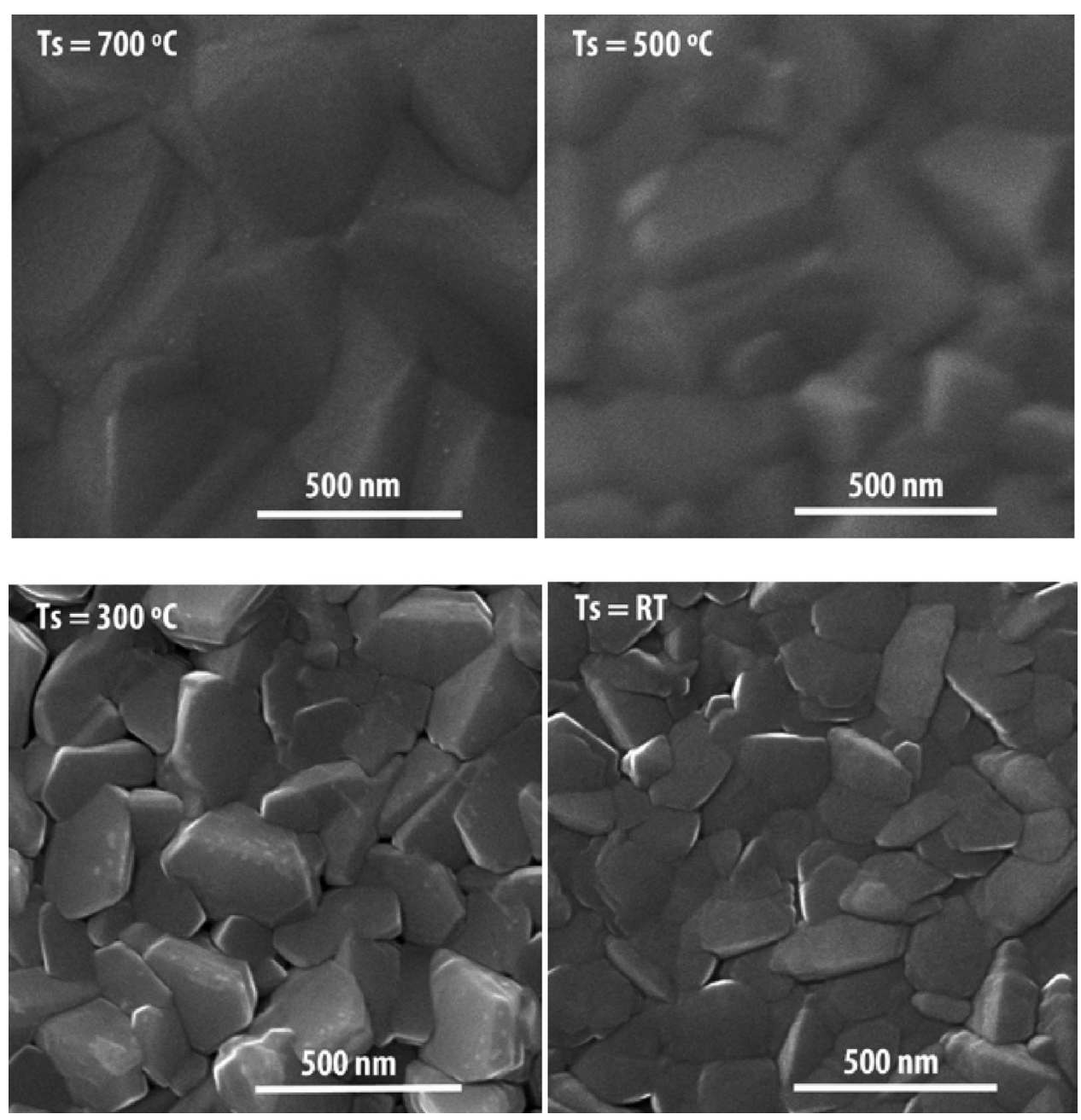

Fig. 3. SEM images of the surface morphology of titanium layers deposited at different substrate temperatures.

increased from RT to $700^{\circ} \mathrm{C}$. That indicates an improvement of the crystallization at high substrate temperature.

The surface morphology of the Ti films deposited at different substrate temperatures on SS substrate was studied by SEM and the results are shown in Fig. 3. At low substrate temperature (lower than $300^{\circ} \mathrm{C}$ ), the flat sheet grains are loosely packed together. It will form titanium films with a porous structure as it can be seen in Fig. 3. When the substrate temperature is higher than $500^{\circ} \mathrm{C}$, these flat sheet grains change into the nubby grains and the films become relative dense compared with films grown at the temperature lower than $300^{\circ} \mathrm{C}$. This densification is necessary to avoid the corrosion of the SS substrate by electrolyte. It also can be seen from Fig. 3 that the grain size in the sample surface increases as the substrate temperature is increased. Both the increase of the grain size and the densification of the film indicate the improvement of the crystallization of the titanium films at high substrate temperature. The microstructure of sputtered metal films is usually classified by structure-zone models [19]. Microstructures in zone $1(\mathrm{Ts} / \mathrm{Tm}<0.3$, where Ts is the substrate temperature and Tm melting point of the deposited material) consisted of tapered columns which are separated by voided boundaries. Zone $2(0.3<\mathrm{Ts} / \mathrm{Tm}<0.5)$ microstructures consisted of columnar grains separated by dense intercrystalline boundaries. Zone $3(0.5<\mathrm{Ts} / \mathrm{Tm}<1)$ microstructures consisted of more equiaxied grains. For titanium metal, the melting point is about $1660^{\circ} \mathrm{C}$. When the substrate temperature is lower than $300^{\circ} \mathrm{C}$, Ts/Tm is less than 0.3. According to the Thornton structure-zone model, the deposited films should have tapered columns structure. However, the structure shown in Fig. 3 does not agree with the model. It shows the flat sheet grains with voids between them. When the substrate temperature is increased from $500^{\circ} \mathrm{C}$ to $700^{\circ} \mathrm{C}$, the values of Ts/Tm locate in zone 2 . Again, no columnar grains separated by dense intercrystalline boundaries structure have been observed. Instead of that, the equiaxied grains have been observed. Although the Thornton structure model cannot be applied directly to these titanium films prepared by dc magnetron sputtering technique, the general statement of the original Thornton model is maintained: increasing the substrate temperature leads to a more compact and dense film structure.

Figure 4 shows the photocurrent density as a function of voltage of DSSCs assembled using SS coated with titanium films deposited at different temperatures as the substrates. For comparison, the results of the DSSC assembled using titanium sheet and FTO glass as the substrates have also been given in Fig. 4. The corresponding photovoltaic parameters of these fresh cells (short-circuit current density, $J_{\mathrm{sc}}$; open-circuit voltage, $V_{\mathrm{oc}}$; fill factor, FF and conversion efficiency, $\eta$ ) are listed in Table 1 (The accuracies of the measurements for $V_{\mathrm{oc}}$ and $J_{\mathrm{sc}}$ are in order of $10^{-3} \mathrm{~V}$ and $10^{-3} \mathrm{~mA} / \mathrm{cm}^{2}$, respectively). From Table 1 it can be seen that the photocurrent density increases as the substrate temperature is increased. It means that the high deposition temperature of titanium film is favorable for increasing the photocurrent density. The photocurrent density $J_{s c}$ depends on the charge injection and collection. Charge injection efficiency is determined by several factors such as 


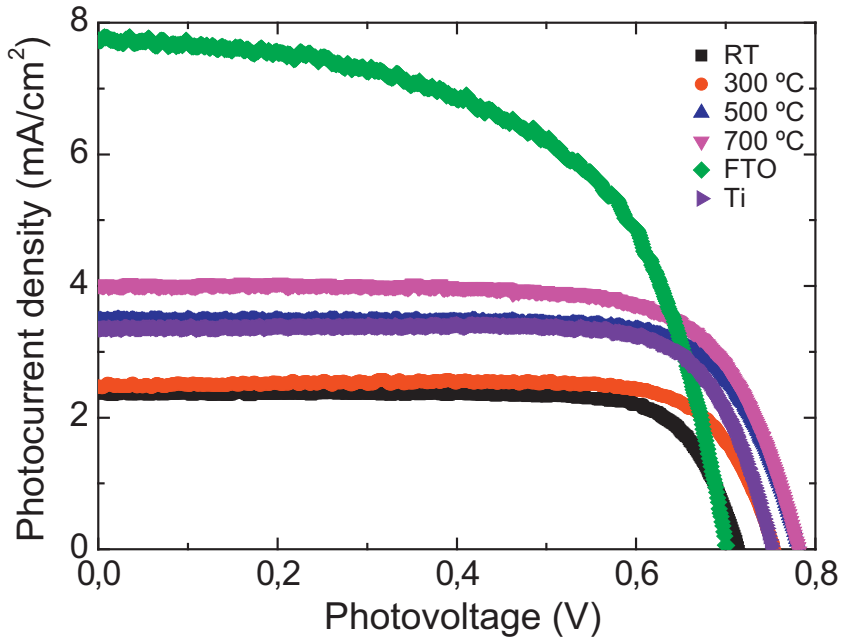

Fig. 4. Photocurrent-voltage curves of the devices based on different substrates.

potential difference between the conduction band edge of $\mathrm{TiO}_{2}$ and lowest unoccupied molecular orbital of the adsorbed dyes, acceptor density in $\mathrm{TiO}_{2}$, and spatial distance between the surface of $\mathrm{TiO}_{2}$ and the dye. As these DSSCs are assembled using the same process, the only difference is the substrate, the charge injection efficiency should not have any difference for them. Therefore the difference of the $J_{\mathrm{sc}}$ must come from the difference of the charge collection efficiency. Although electron diffusion length is a key point for the charge collection efficiency, it does not dominate the variation of the $J_{s c}$ in these DSSCs as the $\mathrm{TiO}_{2}$ photoelectrodes are made by the same process. The difference of the $J_{\mathrm{sc}}$ should come from the difference of the interface between the conducting sheet and $\mathrm{TiO}_{2}$. The DSSC assembled using the titanium film deposited at the temperature higher than $500^{\circ} \mathrm{C}$ on SS has higher charge collection efficiency than that using titanium metal sheet has. This phenomenon may be related with the structure of the titanium film deposited at different substrate temperatures. As it can be seen from Fig. 3 that the titanium films prepared at the substrate temperature lower than $300^{\circ} \mathrm{C}$ consisted of separated flat sheet grains with voids between them. These voids may result in the loss of the electrons and decrease the charge collection efficiency. When the temperature is higher than $500^{\circ} \mathrm{C}$, the voids between the grains disappear, the electrons which reach the conducting layer will be extracted to external load without any loss and result in an increase of the photocurrent density. The origin of photovoltage has not yet been understood. Gregg et al. have suggested that $V_{\mathrm{oc}}$ is most likely related with the difference between the Fermi level of semiconductor electrode and redox potential [20]. Our results do not agree well with this suggestion. As the $\mathrm{TiO}_{2}$ photoelectrode and the electrolyte are the same for all DSSCs, the difference between the Fermi level of semiconductor electrode and redox potential should not have any difference. So the $V_{\mathrm{oc}}$ should be the same for all DSSC. However, the $V_{\mathrm{oc}}$ is different for different substrates as it can be seen from Table 1 . Again it can be seen that the high deposition temperature of titanium film is favorable for the $V_{\text {oc }}$. However, high deposition temperature

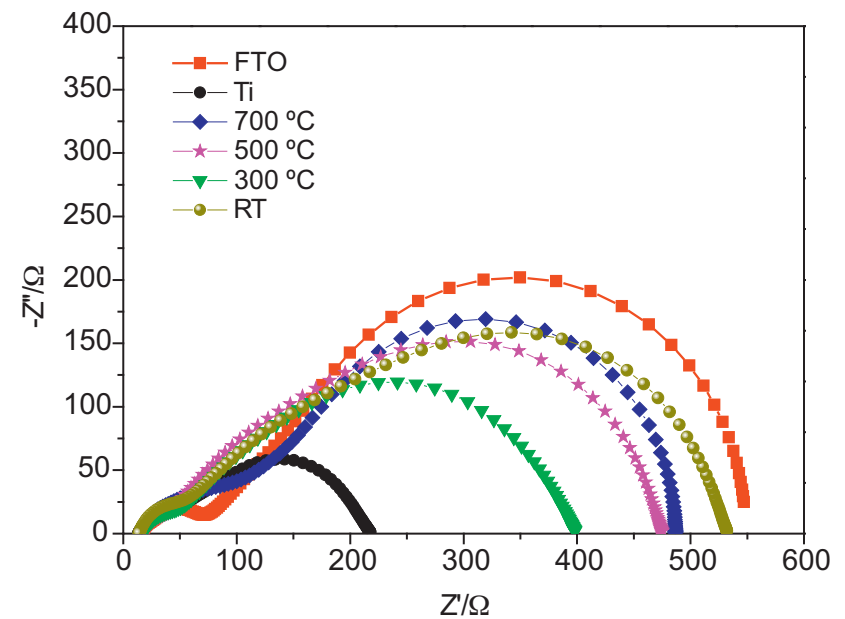

Fig. 5. Nyquist plots of the DSSC assembled with different substrates.

of titanium film is not favorable for the FF. For comparison, the parameters of the DSSC assembled with FTO glass substrate are also given in Table 1. It can be seen that the photocurrent is much higher than the DSSC assembled with titanium metal and SS coated by titanium film substrates. However, the FTO based DSC has the lowest $F F$. This may indicate the presence of large resistive losses at the electrode-substrate junction as the electrical resistance of FTO substrate is an order of magnitude higher than titanium coated SS substrates. It means FTO substrate has lower charge collection efficiency than titanium. The DSSC assembled using FTO substrate has highest conversion efficiency, this could be ascribed to the large charge recombination for FTO-free based DSSCs. The DSSC assembled with SS coated by titanium film at high substrate temperature shows higher conversion efficiency than that assembled using titanium metal sheet. The efficiency of the DSSC assembled with SS coated by titanium film at $700^{\circ} \mathrm{C}$ has reached about $70 \%$ of the efficiency of the DSSC assembled with FTO glass substrate.

To compare the interfacial charge transfer resistance, electrochemical impedance spectroscopy (EIS) was measured. Figure 5 shows typical Nyquist plots of the DSSC assembled with different substrates. A suggested equivalent circuit representing the DSSC is shown in Figure 6. The intercept on the real axis corresponds to the series resistance $\left(R_{\mathrm{S}}\right)$ where the phase is zero. It represents the resistance of the conductive materials in the DSSC with contributions from the SS substrate, $\mathrm{TiO}_{2}$ photoanode, current collector and resistivity of the electrolyte [21]. Besides, there are three semicircles, from left to right, the left one can be ascribed to counter electrode/electrolyte interface consisted of the charge transfer resistance $\left(R_{\mathrm{ct}}(\mathrm{CE})\right)$ and the capacitance $C_{\mu}(\mathrm{CE})$; the middle one can be ascribed to photoanode/electrolyte interface consisted of the charge transfer resistance $\left(R_{\mathrm{ct}}(\mathrm{AE})\right)$ and the capacitance $C_{\mu}$ $(\mathrm{AE})$; the right one can be ascribe to the Nernst diffusion impedance $\left(Z_{N}\right)$. The EIS parameters for the equivalent circuit of the DSSC are also listed in Table 1 . No clear correlation between the series resistance $R_{\mathrm{S}}$ and the conversion efficiency has been found in this work.

Table 1

Photovoltaic and EIS parameters of the DSSC based on different substrates.

\begin{tabular}{|c|c|c|c|c|c|c|c|c|}
\hline & $J_{\mathrm{sc}}\left(\mathrm{mA} / \mathrm{cm}^{2}\right)$ & $V_{\text {oc }}(\mathrm{V})$ & $\mathrm{FF}$ & $\eta(\%)$ & $R_{\mathrm{s}} / \Omega$ & $R_{\mathrm{ct}}(\mathrm{CE}) / \Omega$ & $R_{\mathrm{ct}}(\mathrm{AE}) / \Omega$ & $Z_{N} / \Omega$ \\
\hline FTO & 7.74 & 0.70 & 0.58 & 3.15 & 16.8 & 24.3 & 23.3 & 482.6 \\
\hline Ti sheet & 3.34 & 0.75 & 0.79 & 1.98 & 13.3 & 24.9 & 94.6 & 84.9 \\
\hline SS + Ti film deposited at $700^{\circ} \mathrm{C}$ & 4.01 & 0.78 & 0.72 & 2.26 & 14.8 & 24.2 & 45.0 & 402.6 \\
\hline $\mathrm{SS}+\mathrm{Ti}$ film deposited at $500^{\circ} \mathrm{C}$ & 3.47 & 0.78 & 0.75 & 2.04 & 15.4 & 25.6 & 206.8 & 227.2 \\
\hline $\mathrm{SS}+\mathrm{Ti}$ film deposited at $300^{\circ} \mathrm{C}$ & 2.47 & 0.75 & 0.79 & 1.48 & 17.3 & 25.9 & 220.9 & 133.9 \\
\hline SS + Ti film deposited at RT & 2.36 & 0.71 & 0.79 & 1.33 & 13.8 & 25.4 & 261.3 & 231.6 \\
\hline
\end{tabular}




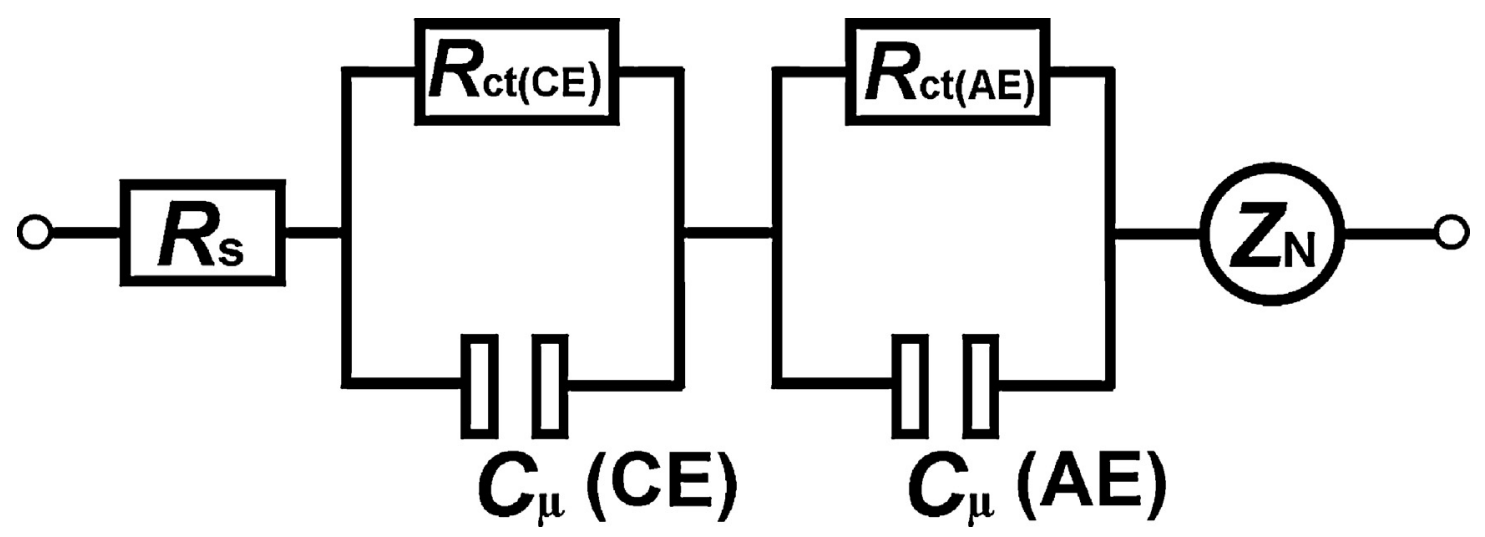

Fig. 6. Suggested equivalent circuit of the DSSC. $R_{\mathrm{S}}$, series resistance, $R_{\mathrm{Ct}}(\mathrm{CE})$, charge transfer resistance in the counter electrode/electrolyte interface; $R_{\mathrm{Ct}}$ (AE), charge transfer resistance in the photoanode/electrolyte interface. $Z_{\mathrm{N}}$, Nernst diffusion resistance.

And the values of the $R_{\mathrm{Ct}}(\mathrm{CE})$ are almost the same for all DSCS as shown in Table 1. It can be said that the conversion efficiency is related with $R_{\mathrm{ct}}(\mathrm{AE})$. It can be seen that for the SS coated with titanium, as the substrate temperature is increased from the room temperature to $700^{\circ} \mathrm{C}$, the value of $R_{\mathrm{ct}}(\mathrm{AE})$ decreased from 261.3 to $45.0 \Omega$, and the conversion efficiency is enhanced from $1.33 \%$ to $2.06 \%$. However, comparing to FTO, the best SS still shows inferior behavior, evidenced by the difference on $R_{\mathrm{ct}}(\mathrm{AE})$ and conversion efficiency. The only difference for these DSSCs is the substrate as all the DSSCs should have the same photoelectrode/electrolyte and counter electrode/electrolyte interfaces. Therefore, it is suggested that the difference of this charge transfer resistance results from the $\mathrm{TiO}_{2} / \mathrm{Ti}$ interface. According to the EIS data, there may exit a large charge recombination in the $\mathrm{TiO}_{2} / \mathrm{Ti}$ interface, and this is adverse to change collection efficiency. Fortunately, improve the substrate temperature can lower the charge transfer resistance and inhibit charge recombination in the $\mathrm{TiO}_{2} / \mathrm{Ti}$ interface, resulting in a high photocurrent density and then a high efficiency which is agreeable with efficiency measurement.

\section{Conclusions}

DSSCs have been assembled using titanium metal sheet, titanium film coated flexible SS sheets and FTO as substrates. Titanium film deposited at high substrate temperature (higher than $500^{\circ} \mathrm{C}$ ) shows a very dense structure. The DSSC assembled using SS sheet coated by titanium film prepared at high substrate temperature has a low charge transfer resistance in the $\mathrm{TiO}_{2} / \mathrm{Ti}$ interface and leads to a high conversion efficiency. The conversion efficiency of the DSSC assembled using SS sheet coated by titanium film at $700{ }^{\circ} \mathrm{C}$ is $2.26 \%$, which is $70 \%$ of the FTO reference cell (3.15\%).

\section{Acknowledgment}

This work was supported by the Dalian University of Technology through the program of the Sea-sky Scholar.

\section{References}

[1] B. Oregan, M. Gratzel, A. Low-Cost, High-efficiency solar-cell based on dyesensitized colloidal $\mathrm{TiO}_{2}$ films, Nature 353 (1991) 737-740.

[2] Y. Chiba, A. Islam, R. Komiya, N. Koide, L.Y. Han, Conversion efficiency of $10.8 \%$ by a dye-sensitized solar cell using a $\mathrm{TiO}_{2}$ electrode with high haze, Applied Physics Letters 88 (2006) 223505.
[3] K. Wessels, M. Wark, T. Oekermann, Efficiency improvement of dye-sensitized solar cells based on electrodeposited $\mathrm{TiO}(2)$ films by low temperature posttreatment, Electrochimica Acta 55 (2010) 6352-6357.

[4] H.W. Chen, C.P. Liang, H.S. Huang, J.G. Chen, R. Vittal, C.Y. Lin, K.C.W. Wu, K.C. Ho, Electrophoretic deposition of mesoporous $\mathrm{TiO}(2)$ nanoparticles consisting of primary anatase nanocrystallites on a plastic substrate for flexible dye-sensitized solar cells, Chemical Communications 47 (2011) 8346-8348.

[5] D. Gutierrez-Tauste, I. Zumeta, E. Vigil, M.A. Hernandez-Fenollosa, X Domenech, J.A. Ayllon, New low-temperature preparation method of the $\mathrm{TiO}_{2}$ porous photoelectrode for dye-sensitized solar cells using UV irradiation, Journal of Photochemistry and Photobiology A 175 (2005) 165-171.

[6] Z. Lan, J.H. Wu, Flexible dye-sensitized solar cells, Progress in Chemistry 22 (2010) 2248-2253.

[7] K. Fan, T.Y. Peng, J.N. Chen, K. Dai, Effects of tetrabutoxytitanium on photoelectrochemical properties of plastic-based $\mathrm{TiO}(2)$ film electrodes for flexible dye-sensitized solar cells, Journal of Power Sources 196 (2011) 2939-2944.

[8] H.W. Chen, Y.T. Liao, J.G. Chen, K.C.W.Wu, K.C. Ho, Fabrication and characterization of plastic-based flexible dye-sensitized solar cells consisting of crystalline mesoporous titania nanoparticles as photoanodes, Journal of Materials Chemistry 21 (2011) 17511-17518.

[9] T. Yamaguchi, N. Tobe, D. Matsumoto, T. Nagai, H. Arakawa, Highly efficient plastic-substrate dye-sensitized solar cells with validated conversion efficiency of 7.6\%, Solar Energy Materials and Solar Cells 94 (2010) 812-816.

[10] T. Yamaguchi, N. Tobe, D. Matsumoto, H. Arakawa, Highly efficient plastic substrate dye-sensitized solar cells using a compression method for preparation of $\mathrm{TiO}_{2}$ photoelectrodes, Chemical Communication 43 (2007) 4767-4769.

[11] Y. Jun, J. Kim, M.G. Kang, A study of stainless steel-based dye-sensitized solar cells and modules, Solar Energy Materials and Solar Cells 91 (2007) 779-784.

[12] Y. Jun, M.G. Kang, The characterization of nanocrystalline dye-sensitized solar cells with flexible metal substrates by electrochemical impedance spectroscopy, Journal of the Electrochemical Society 154 (2007) B68-B71.

[13] H.G. Yun, B.S. Bae, M.G. Kang, A. Simple, Highly efficient method for surface treatment of Ti substrates for use in dye-sensitized solar cells, Advanced Energy Materials 1 (2011) 337-342.

[14] H.G. Yun, Y. Jun, J. Kim, B.S. Bae, M.G. Kang, Effect of increased surface area of stainless steel substrates on the efficiency of dye-sensitized solar cells, Applied Physics Letters 93 (2008) 133311

[15] J.J.Yun, T.Y. Kim, S.Y. Cho, E.M. Jin, H.B. Gu, K.H. Park, Electrochemical properties of platinized counter electrode on based stainless steel sheet for dye-sensitized solar cells, Journal of Chemical Engineering of Japan 41 (2008) 639-643.

[16] M.G. Kang, N.G. Park, K.S. Ryu, S.H. Chang, K.J. Kim, Flexible metallic substrates for $\mathrm{TiO}_{2}$ film of dye-sensitized solar cells, Chemistry Letters 34 (2005) 804-805.

[17] M.G. Kang, N.G. Park, K.S. Ryu, S.H. Chang, K.J. Kim, A 4.2\% efficient flexible dyesensitized $\mathrm{TiO}_{2}$ solar cells using stainless steel substrate, Solar Energy Materials and Solar Cells 90 (2006) 574-581.

[18] V. Vijayakumar, A. Du Pasquier, D.P. Birnie, Electrical and optical studies of flexible stainless steel mesh electrodes for dye sensitized solar cells, Solar Energy Materials and Solar Cells 95 (2011) 2120-2125.

[19] J.A. Thornton, The microstructure of sputter-deposited coatings, Journal of Vacuum Science and Technology A 4 (1986) 3059-3066.

[20] F. Pichot, B.A. Gregg, The photovoltage-determining mechanism in dyesensitized solar cells, Journal of Physical Chemistry B 104 (2000) 6-10.

[21] T. Denaro, V. Baglio, M. Girolamo, V. Antonucci, A.S. Arico, F. Matteucci, R. Ornelas, Investigation of low cost carbonaceous materials for application as counter electrode in dye-sensitized solar cells, Journal of Applied Electrochemistry 39 (2009) 2173-2179. 